\title{
EL CONCEPTO PERÚ EN EL IMAGINARIO NACIONAL
}

Fausto Alvarado Dodero

Universidad Pablo de Olavide, Sevilla

\begin{abstract}
RESUMEN
El concepto Perú se forja recién con el contacto del mundo andino con Europa, individualizado en la presencia por el rey de España. Inicialmente con una serie de fonemas muy parecidos que aparecen en el lenguaje castellano y se uniformizan bajo la voz Perú, sustantivándose para referirse espacialmente al sur de Panamá y también adjetivándose como riqueza. Finalmente adquiere valor político con la creación del virreinato en 1542, quedando delimitado su espacio físico y conceptual, totalmente alejado de la percepción semántica del concepto colonia, cuyo significado sólo alcanza a la emigración a territorios yermos para su poblamiento o defensa.
\end{abstract}

PALABRAS CLAVE

Perú / Voz / Sustantivo / Concepto / Colonia / Virreinato.

\begin{abstract}
The new concept is shaped Peru with the Andean world contact with Europe, individualized in the presence of the king of Spain. Initially a series of very similar phonemes and voices that appear in the Castilian language and standardize under Peru like a noun to refer spatially south of Panama and also like Adjective as wealth. Finally acquires political significance with the creation of the viceroyalty in 1542 , being delimited physical and conceptual space, completely away from the perception of the concept semantic colony, meaning only reaches emigration to barren lands for settlement or defense.
\end{abstract}

KEY WORDS

Peru, Voice / Noun / Adjective / Concept / Colony / Viceroyalty. 


\section{INTRODUCCIÓN: MARCO TEÓRICO. LOS CONCEPTOS EN EL TIEMPO Y EN EL ESPACIO}

Con el tiempo se producen cambios en el significado de los conceptos, incorporando y expulsando capas semánticas y modificando el campo de su significado. Sin embargo, en la continuidad de esos cambios se desarrolla una identificación entre el sujeto y el objeto, que en este caso es el sentido de pertenencia de seres humanos al ser humano peruano, como afirma Francisco Tomás y Valiente en cita recogida por Javier Fernández Sebastián": "los conceptos y las instituciones no nacen en un vacío puro e intemporal, sino en lugar y fecha conocidos y a consecuencia de procesos históricos" (Fernández, 2004, p. 6). Para la historia conceptual no todo concepto es objeto de estudio, sino aquellos que tienen contenido político y significación en la sociedad, que el lenguaje atrapa y mantiene su significado en un tiempo y en un espacio determinado. En ese orden de ideas los conceptos son el resultado de un proceso de sucesivos hechos históricos que van modificado su significado. En este artículo hacemos una descripción del discurrir del concepto Perú en su espacialidad y temporalidad, desde su incorporación al lenguaje como voz o vocablo, sus sustantivación y adjetivación, hasta llegar a nuestros días y observar cómo el imaginario nacional lo concibe.

El recorrido del vocablo desde sus inicios poco antes de las expediciones pizarristas, fue recogiendo una serie de capas semánticas que entraron en un proceso de sistematización de ideas y referencias, para que la expresión Perú reuniera las suficientes que la calificara como concepto, como "una idea que concibe y forma el entendimiento" concepto no sólo tiene comprensión sino extensión. Todo esto en el marco lingüístico, que en el plano filosófico se expresa como representación mental teniendo validez objetiva en su conocimiento. Pero en el concepto histórico se define como "su capacidad de trascender su contexto originario y proyectarse en el tiempo" (REGALADO, 2010, p. 416). Esta apreciación reviste gran importancia, porque como afirma Reinhart Koselleck, "sin conceptos no hay experiencia histórica ni conocimiento histórico" (Koselleck, 1972, p. 13). Tenemos así una reunión diacrónica de significados,

1 Javier Fernández Sebastián, catedrático de Historia del Pensamiento Político en la Universidad del País Vasco, director del Proyecto del Historia Conceptual, constitucionalismo y modernidad en el mundo iberoamericano. Lenguaje y conceptos políticos-jurídicos fundamentales.

2 Definición del DRAE, 2001, 414) 
que como capas semánticas se van incorporando o alejando por hechos relevantes de la vida humana.

Volviendo al terreno que nos ocupa, no tenemos duda que el concepto Perú, con la formación del virreinato que lleva su nombre, cumplió con todos los requisitos para constituir un concepto lingüístico, filosófico histórico y político. Sino revisemos. Lingüísticamente el vocablo que empezó como referencia vaga, conforme van sucediendo los hechos se constituye en una idea que concibe el entendimiento de tal forma que su sola palabra hace entender su referencia. Filosóficamente, la mención a Perú implica inmediatamente una representación mental de algo objetivo. Como concepto histórico hay un conjunto de experiencias y hechos trascendentales que actúan como agentes de cambio semántico, y finalmente, político porque refleja una forma territorial de gobierno donde se ejerce poder

\section{PERÚ DE VOCABLO A CONCEPTO}

Los andinos debe ser la referencia a los pobladores de la Cordillera de Los Andes, que conocieron los hombres europeos cuando llegaron a esas tierras. Genéricamente llamados indios, sólo porque ocupaban las Indias Occidentales constituyendo una referencia geográfica de su tiempo, o indígenas por su origen, término este último que sólo debe utilizarse para referirse a los nativos o naturales cuando no tienen nombre específico, que en nuestro caso existe desde la incorporación del vocablo Los Andes al lenguaje castellano, como sustantivo propio para identificar a la cordillera, y por ende su gentilicio andinos para identificar a sus pobladores.

El nombre propio actual de la cordillera sudamericana sólo lo podemos remontar a la llegada del hombre europeo, dado que no hay referencia, o por lo menos no conocemos el nombre, que en cualquiera de las lenguas andinas, se le haya dado a este componente orográfico, dejando constancia de las no muy convincentes versiones que existen al respecto. ${ }^{3}$ Dicho de otro modo, cómo los antiguos pobladores llamaban a la cordillera, resultando poco probable que la hubieran definido en términos geográficos, ni que le hubieran atribuido un nombre propio, tarea que en todo caso queda para la onomástica geográfica.

3 Véase, Tantaleán, 2011, Vol. I, p. 84, n. 4. 
Igual sucede con el vocablo Perú y por derivación peruano. La palabra viene con los peninsulares europeos y responde más a una deformación fonética que a una toponimia pretérita a ese tiempo. En otras palabras, Perú como vocablo existe a partir de ese encuentro, para referirse a un territorio al sur de la presencia hispánica en Centro América y el Caribe. Porras afirma categóricamente que "el nombre del Perú fue desconocido por los incas, fue impuesto por los conquistadores y rechazado por los indios del Perú, que se negaban a usarlo, según el testimonio de Valera, Acosta y Garcilaso" (Porras, 2011, p. 188).

En cualquiera de las versiones la situación no cambia, sea la asumida a partir de Pascual de Andagoya ${ }^{4}$ o la que fuera cierta, no escapa, que antes de la llegada de europeos a Sudamérica Occidental, no podríamos referirnos a peruano ni a Perú. Poco cabe hurgar, ya sea en la versión de Pascual de Andagoya $^{5}$ de haber ido a una provincia de nombre Perú, la de Gaspar de Morales 6 , la conexión a "peruqueta"7 , la del cronista González Fernández de Oviedo $^{8}$. Así como la de Estete, Alcedo, el padre Acosta, Blas Valera, Calancha, el padre Cappa o Lafaye ${ }^{9}$, o la del cronista Gutiérrez de Santa Clara quien le atribuye a Francisco de Becerra "ser el primer hombre que tuvo

4 Pascual de Andagoya llega al sur de la actual Colombia en 1523. (Tenenti, 2011, p. 153). Andagoya cuenta: "supe como por mar venían cierta gente en canoas a hacerles guerra todas las lunas llenas, y tenían tanto miedo que aquella gente los de aquella provincia, que no osaban ir a la mar a pescar; estos eran de una provincia que se dice Birú, donde corrompido el nombre se llamó Pirú". También mencionamos que en "la concesión del escudo de armas por el emperador, Andagoya, en el 39, llega a decirse que descubrió la provincia del Perú". (Ramos, 2008. p. 161).

5 Miguel Maticorena Estrada dedica uno de sus artículos a este peninsular: El vasco Pascual de Andagoya, inventor del nombre Perú, Cielo Abierto, V, Lima, 1779. Que Bernard Lavallé recoge para exponer la tesis que la palabra Pirú o Perú provenía del cacique Birú. (Lavallé, 2005, p. 53).

6 Capitán español que menciona a un cacique de nombre Birú.

7 Peruqueta era una referencia a una provincia "de una mar a otra" (Ramos, 2008, p. 161).

8 Gonzalo Fernández de Oviedo cronista autor de Historia General y natural de las Indias.

9 Javier Tantaleán Arbulú dedicó un capítulo entero "Sobre el Embrión de la Voz Perú" en el cual trata en detalle las versiones de estos cronistas y opiniones de otros autores como Franklyn Pease, Rostoworoski, Porras, Macera y además muestra la Carta del Nuevo Mundo de 1529 de Diego de Ribero en que aparece el nombre de Perú en el emplazamiento geográfico que corresponde (Tantaleán, 2011,Vol. 1, pp. 79-94). 
noticias de esta tierra del Perú”. (Ramos, 2008, pp. 161-162), cuya versión no sólo la circunscribe al lugar sino también al nombre del cacique. ${ }^{10}$

Una de la primeras derivaciones para referirse al hombre del Perú o proveniente del Perú, fue la de peruleros, que el diccionario establece como sinónimo de peruano y también como aquel, que con mucha riqueza desde Perú regresa a España, constituyendo un sustantivo propio y con espacio en la historia económica de la época. No está de más recordar la crisis económica que originó en Europa la llegada del primer cargamento de plata, al afectar sustantivamente la relatividad de los precios de los bienes y servicios con el valor de ese metal, que estaban determinados por su escasez, y al aparecer en abundancia, remeció toda la actividad económica en el viejo continente y en otros lugares del mundo conocido entonces.

El concepto Perú se forja recién con el contacto del mundo andino con Europa, individualizado en la presencia por el rey de España. Inicialmente con una serie de fonemas muy parecidos que aparecen en el lenguaje castellano y se uniformizan bajo la voz Perú, sustantivándose para referirse espacialmente al sur de Panamá y también adjetivándose como riqueza. Finalmente adquiere valor político con la creación del virreinato en 1542, quedando delimitado su espacio físico y conceptual. Esto no es de carácter inmediato, sino un proceso cognoscitivo, que pasa primero por una referencia vaga sobre algo ignoto y por conocer, aunque de manera inminente, lo cual nos remonta a las expediciones de Pizarro y a la Capitulación de Toledo, en que el sustantivo adquiere madurez semántica y podemos afirmar, siguiendo a Mark Thurner, que se constituye en uno de los primeros sujetos "de la moderna imaginación histórica", que "coincide con el amanecer de la edad global o moderna" (Mark Thurner, En nombre del Abismo. Meditaciones sobre la historia de la historia. Lima: Instituto de Estudios Peruanos, 2012, p. 15).

En planos temporales y espaciales, debemos estudiar la evolución del concepto Peruano, en carne de asociado del concepto Perú, mediante

10 Hidefuji Somada en la primera parte de su obra El Imperio de los Incas. Imagen del Tahuantinsuyo creada por los cronistas, dedica sus tres capítulos a las crónicas y primeras informaciones e Invención de los cronistas sobre el Reino del Perú, donde se puede recurrir para mayores detalles sobre las primeras voces referidas a los territorios andinos. (Someda, 2005, pp. 15-77). Así mismo, sobre la sucesión inca en Vilcabamba se puede revisarla obra de Liliana Regalado de Hurtado: Sucesión Incaica. (Regalado, 1996, pp. 113-123) 
el significado espacial de este último desde su incorporación al lenguaje castellano, primero, como una referencia fonética de carácter geográfico y de gran esplendor y riqueza. Y luego, con Ideas y representaciones que le van dando vida propia, sistematizándolas y sustantivándose, y hasta adjetivándose para significar algo muy apreciado y grandioso ${ }^{11}$, sintetizado en la frase "vale un Perú". También como peruleros refiriéndose a aquellos que volvían desde el Perú a España cargados de tesoros.

Inicialmente el territorio al sur de Panamá, a partir de la llegada de los enviados del rey de Castilla, es conocido como "la costa del Levante", así consta en todos los documentos de Panamá y de la Corte anteriores a 1527, conforme indica Raúl Porras, quien además, deja testimonio, en el sentido que la primera referencia al viaje de Pizarro en busca de nuevas tierras, está en la carta de Pedrarias al Rey del mes de abril de 1525, en la que dice: "al Levante, por la Mar del Sur tengo enviada otra armada, como le he escrito a V.M. a descubrir, con el capitán picarro, mi teniente del Levante" (Porras, 2011, p. 169) ${ }^{12}$. Aparecen luego una serie de vocablos fonéticamente en la dirección de Perú, pero no precisamente con ese texto ni con ese fonema, como Birú, Pirú, etc. Posteriormente, el vocablo va tomando forma y queda construido como Perú.

Adquiere nombre propio con las Capitulaciones de Toledo en 1529, luego toma connotación política y nacional con la creación del Virreinato en 1542, para continuar en la época republicana tal como llega a nuestros tiempos, no sin antes, reducir el campo espacial del concepto, por la pérdida de importantes territorios, tanto en la época virreinal, como en la republicana.

El concepto Peruano va tomando sentido unitario, para comprender en su significado, a todos los seres humanos que nacen dentro en la unidad política o se adhieren por afinidad a la nación peruana, sin afirmar que dicho proceso haya terminado, pero si caminando en esa dirección, recorriendo este camino hasta nuestros días, pero partiendo desde la época virreinal, en tiempos que compartimos una misma historia con los demás reinos de la monarquía española o por lo menos conectadas, pero sin dejar de mirar

11 El cronista Alonso Enríquez de Guzmán (Sevilla, 1501-1542), que llega a Lima recién fundada la ciudad de Los Reyes oye en Santo Domingo antes de su arribo sobre la fama de Perú: "ay infinita cantidad de oro sin quenta ni sin medida" y “do yerro precian más que oro, la plata danla de valde". (Carrillo, 1989, p. 21).

12 Porras recoge esta cita de José Toribio Zavala en Colección de documentos inéditos para la Historia de Chile. Tomo VI. Santiago de Chile, pp. 26-27. 
el escenario anterior a este punto de partida, ya que el concepto Perú en el presente comprende ese pasado al que la historiografía se refiere como prehispánico, en sus dos tiempos Incaico y Preincaico.

Entre estas especies de tambos históricos conceptuales, utilizamos varias líneas dedicadas al periodo entre la llegada de Pizarro y la creación del Virreinato en 1542, postulando denominarla Periodo de Transición Imperial o Pre Virreinal si se quiere, debido a que se estuvo, no frente a una conquista propiamente dicha, sino al traslado o tránsito político, social, económico e ideológico ${ }^{13}$ de un imperio a otro, entre el Incaico y el de la Monarquía Austro Española y del cambio de un rey por otro, que en líneas generales militarmente hablando fue pacífico, evidentemente que esto no alcanza al enorme trauma cultural, social y de otra índole que causó este hecho. Así mismo las condiciones en que el Reino del Perú gobernado por el propio rey representado como su alter ego en el virrey, es introducido por la Monarquía Católica en su estructura política incorporado a la corona de Castilla como parte del reino de Indias. Pero no como colonia.

Finalmente, luego de configurarse como sustantivo toma connotación política y nacional con la creación del Virreinato en 1542, para continuar en la época republicana tal como llega a nuestros tiempos, no sin antes reducir el campo espacial del concepto, por la pérdida de importantes territorios, tanto en la época virreinal como en la republicana. No está demás precisar que el Virreinato del Perú en $1739^{14}$ fue reducido con la creación del virreinato de Nueva Granada y posteriormente en $1777^{15}$ con la creación del Virreinato del Río de la Plata. Luego de constituida la República Peruana vinieron nuevas pérdidas territoriales en época que también son significativas y por demás conocidas $^{16}$, que afectaron el ámbito espacial del concepto Perú.

13 Un cambio fundamental fue en el aspecto ideológico, principal y casi totalmente focalizado en el campo religioso, ya que la misión de España, real o aparente para los escépticos, era difundir la religión católica y eso pasaba por sustituir por completo todas las manifestaciones divinas del mundo andino que no pudieran sincretizarse o refundirse en la católica.

14 Si bien es cierto el Virreinato de Nueva Granada se creó en 1717 fue suspendido en 1723 y recién en 1739 se implementó.

15 Se creó provisionalmente en 1776 y en forma definitiva en 1777.

16 Raúl Porras Barrenechea hizo un amplio estudio sobre la historia de los límites del Perú (Porras, p. 2011) 


\section{EL PERÚ EN EL IMAGINARIO NACIONAL}

El nacimiento político del virreinato permitió ir paulatinamente identificando y reconociendo a un hombre peruano, como aquel nacido en este reino. El cambio viene cuando los Borbones desplazan a la dinastía de los Habsburgo a inicios del siglo XVIII y la Monarquía Católica con sede en Madrid, emprende una serie de reformas, destinadas a centralizar el poder y concentrarlo absolutamente en el monarca.

Las reformas borbónicas más estuvieron dirigidas para aplicarse a los virreinatos en Europa, dentro y fuera de la península. Afirmar el poder monárquico sobre ellos. No está demás señalar que la historiografía de nuestros tiempos, como lo ha dejado claramente establecido Manuel Rivero Rodríguez, Catedrático de Historia de la Universidad Autónoma de Madrid, en su reciente publicación "La Edad de Oro de los Virreyes" (Madrid, AKAL Universitaria, 2011), ha recargado excesivamente el estudio de los virreinatos hacia los americanos, en detrimento del estudio de los virreinatos que la Monarquía Española tuvo en la propia península, como Portugal, Valencia, Cataluña, Aragón, entre otros y en el resto de Europa, principalmente en los territorios que hoy ocupa Italia, como Sicilia, Cerdeña, Nápoles y otros más. Haciendo casi pensar que los únicos virreinatos de aquellos tiempos fueron Perú y México.

Volviendo a las reformas borbónicas, estas tenían como finalidad principal acabar con todos los fueros y privilegios, especialmente de los poderes nativos de cada uno de los reinos que la conformaba, que debían quedar sometidos a un rey y a un solo derecho, pasando de los virreinatos a las intendencias, y en cuanto a América, buscar el mayor beneficio posible, que era en el fondo convertir los virreinatos existentes, México y Perú, en una suerte de colonias similares a las que Inglaterra y Francia dominaban en territorio americanos.

Imponer estas reformas en los reinos europeos que formaban parte de la monarquía le costó muy caro, en algunos casos fue a sangre y fuego, sin embargo de una u otra manera, no hubo desmembramientos en la península, aunque aún es latente este deseo, como hoy apreciamos en Cataluña. El costo más alto fue pagado en América, ya que la respuesta a la intención de establecer relaciones coloniales fue la independencia, surgiendo el concepto nación y el de patria como guía de estos procesos, que en fin de cuentas, terminaron con la construcción de las repúblicas que 
hoy conocemos. En nuestro caso la República Peruana, desvinculada de la Monarquía Católica o Española.

Para imponer las políticas borbónicas, desde la perspectiva peninsular era necesario reducir al Virreinato Peruano, dado que su crecimiento y dominio sobre el territorio andino generaba el temor a una independencia, más aún cuando había generado una consolidación de los poderes nativos y criollos. Cómo hacerlo. Desmembrado el territorio, y así se generaron los virreinatos de Nueva Granada, en lo que hoy es Colombia y gran parte de Ecuador y Río de La Plata en los que hoy es Argentina, Uruguay, Paraguay y Bolivia.

Lo cual afectó severamente, no sólo en lo político, sino principalmente en lo económico, a los poderes que durante el virreinato se habían constituido, tanto nativos como criollos, como ya lo expresamos. Los cuales al verse afectados tomaron rutas diferentes, pero ambas coincidieron en su destino. Los primeros mediante rebeliones, como la de José Gabriel Condorcanqui, que pasó a la historia como Túpac Amaru II y la de Julián Apaza Nina, que dio el mismo paso como Túpac Catari, y los segundos con la formación de una nación propia. La consecuencia fue la República del Perú.

Encontramos que el sentimiento de peruanidad y en general de pertenencia a los dos grandes virreinatos americanos, empieza a tomar sentido nacional a partir de la reacción frente a esta intención española de imponer un severo régimen político y económico, ya que legitima la idea de emanciparse del yugo monárquico y constituir una unidad política separada, sea mediante un gobierno monárquico o republicano como fue el dilema peruano, unitario o federal como fue el dilema mexicano, pero en todo caso totalmente independientes de España. Son tiempos en que toman mucha fuerza los conceptos de Nación, Patria y Ciudadanía también con influencia de las la llegada de las informaciones, ideas y concepciones liberales de la revolución francesa. (Rosas, 2006, p. 227).

El resultado lo conocemos, nació la República del Perú, como unidad política propia. Aquí quiero detenerme para hacer una precisión en cuanto al manejo del concepto Perú mencionando, que en el tiempo va modificando su ámbito espacial, al principio vimos que su significado era para comprender a todo el territorio al sur de Centroamérica, por decirlo en términos generales, luego restringido al ámbito del Virreinato del Perú, que comprendía hasta corrido el siglo XVIII, toda Sudamérica, con excepción de una parte del 
actual Brasil, que fue paulatinamente modificándose corriendo la línea de Tordesillas hacía el occidente hasta la línea marcada por el Tratado de San Ildefonso en 1777, parte de Venezuela y las Guayanas, restringido luego de los desmembramientos que dieron origen a los virreinatos antes mencionados, y finalmente restringido al ámbito actual de la República Peruana, pasando por las pérdidas territoriales de los siglos pasados. Estos hechos políticos son importantes, porque van definiendo el ámbito del hombre peruano, claro solo en esta dimensión geográfica. De manera exprofeso no estoy tocando los procesos interculturales y de adaptación, así como otros aspectos que sin duda van a marcar el concepto hombre peruano.

Y este es el otro hito en la construcción de la peruanidad, ya que empieza un nuevo imaginario basado en los conceptos patria y nación, sin embargo, construir una nación que identifique a todos quienes pueblan un territorio, es un proceso largo en el cual nos encontramos, pero felizmente avanzando y no retrocediendo, y voy a explicar esto. La división política de nuestro territorio republicano ha primado por encima de cualquier división de carácter étnico. Y vamos a demostrarlo. En Piura más se identifican por piuranos que por tallanes, en Trujillo son más trujillanos que moches, en Ancash son más ancashinos que chavines, en Lima son más limeños que ichmas, y así podría dar más ejemplos, en Puno son más puneños que lupacas o uros, igualmente a los tacneños si los identifico como camanchacas no se van a reconocer.

Pero fue en el siglo XX, segunda mitad principalmente, cuando los antibióticos -Fleming ${ }^{17}$ merece un monumento- permitieron controlar las enfermedades bronquiales infecciosas en las ciudades costeñas, especialmente Lima que concentra el tercio de toda la población, y evidentemente otros factores sociales, permitieron una migración nunca antes vista en nuestros Andes, que se potenció con el terrorismo de las últimas décadas del siglo XX, aunque igual hubieran sido las cosas. Y convergieron en la capital, al igual que en otras ciudades costeñas y algunas serranas, migrantes de todas las sangres por decirlo en palabras ya acuñadas, cuyo resultado no ha sido otro que darle mayor contenido a la peruanidad, mezclando gran

17 Alexander Fleming, nacido n 1881 y fallecido en 1955 descubridor de la penicilina. Los antibióticos permitieron enfrentar las enfermedades bronquiales infecciosas que atacaban a los habitantes de la costa central andina. Con anterioridad los remedios existentes no eran suficientes y de poco acceso por lo que el clima en esos lares se hacía pernicioso para la salud, más aún cuando se vivía en precarias condiciones. Lo demás se explica por sí solo. 
parte de las identidades y de otra índole, produciendo un sincretismo cultural y social, que contribuye a homologar los patrones de comportamiento e identificación.

Ha sido en estas circunstancias que las uniones matrimoniales y no matrimoniales no eran sectarias étnicamente hablando, sino que este aspecto era y es totalmente indiferente. Así tenemos que las generaciones posteriores mayormente tuvieron padres de diferentes lugares y diferentes colores y matices, si el padre era characato y la madre moche, el hijo pasa al piso de peruano, dejando de lado la procedencia de los padres y lo que ello significa en materia de costumbres y tradiciones. No puedo hacer una afirmación apodíctica, dado que carezco de fuentes y estadísticas, pero eso lo observo. Obviamente no es absoluto, tampoco quiero decir positivo, no es este el momento de valorar este proceso, sólo de indicar, como en nuestros tiempos, a pesar de cualquier otra consideración, vamos teniendo una identidad común que nos va identificando en una nación, y lo ideal es que en ese camino este presente el respeto a la diversidad y será el propio desarrollo humano, que en los tiempos vaya dando las pautas y en definitiva nos de la cantidad suficiente de elementos que nos permitan identificarnos a todos como el hombre peruano (Con licencia de género).

Antes de terminar quiero hacer mención a dos temas, el primero referente una identidad que muchas veces divide a los peruanos. Esa bárbara distinción que fluye de utilizar mal el concepto andino para referirse exclusivamente a las partes medias y altas de Los Andes, excluyendo a la costa, como si esta perteneciera a otra cordillera. Se debe tener claro que la costa es un territorio perteneciente a Los Andes o acaso Pachacamac, Caral, Las Líneas de Nazca, Chan Chan, Sechín, Huaca de la Luna, Garagay, Puruchuco, Bandurria o San José de Moro no están los Andes.

Y otro es, recusando esa referencia al Perú aplicando el concepto colonia, para identificar el periodo temporal de incorporación del Perú al conglomerado de reinos que formaron la Monarquía Universal Española, como también la ha llamado la historiografía. En lo que se refiere a los siglos XVI y XVII, para nadie le ha quedado duda que la consideración en sus propios tiempos y temporalidad, el concepto colonia en el lenguaje castellano era aplicado en términos de poblamiento. Sin embargo, los anacrónicos del presente utilizan indistinta, indiscriminada y hasta arbitrariamente el concepto colonia para aplicarlo a todos esos tiempos, es decir a los tres siglos. Lo que queremos dejar sentado es que en sus propios tiempos jamás persona alguna utilizó el concepto colonia, a pesar de existir 
el vocablo y el concepto para significar estrictamente de poblamiento y con un valor axiológico positivo. Pero entonces qué ha pasado. Qué ha hecho modificar capas semánticas o introducir otras.

En un trabajo que hemos volcado en el libro Virreinato o Colonia (Lima: Fondo Editorial del Congreso, 2013), mostramos cómo determinados hechos históricos van realizando esta metamorfosis, que principalmente lo centramos en tres aspectos centrales de los siglos XVIII y XIX.

El primero, la presencia borbona a partir de 1700 con el nieto de Luis XIV, Felipe V que reinó 46 años, en cuyo periodo el formato francés se introdujo en la monarquía española, para aplicarse a todo el espacio que dominaba en Europa, y para las Indias pretendiendo, como ya está dicho, convertirlas en colonias a la usanza francesa de dominio en América, que había empezado en el siglo XVII con una finalidad muy distinta a la administración austro española del siglo anterior.

El segundo, la independencia en 1777 de las trece colonias inglesas, que llega a los virreinatos americanos con significados asociados entre independencia y colonia. Con lo que surge el tercero, la incorporación al discurso emancipador, ya que legitima mejor la causa separatista, y el valor axiológico también cambió y se vuelve negativo el concepto colonia, oprobioso, explotador, etc. Con lo que se entra al primer cuarto del siglo XIX. En el siglo veinte la universalización del discurso estructuralista y las teorías del dominio, mayormente bajo los parámetros que fija la historiografía inglesa y francesa, terminan por desconcertar por completo respecto al uso de este concepto, salvo honrosas resistencias, como Guillermo Lohmann Villena, que no se deja arrastrar por la ola que hoy cubre mentes brillantes dedicadas a escribir sobre el pasado con mirada desde el presente.

Sin embargo este concepto de colonia, aun así dicho, tampoco enerva la condición de ser el Perú una unidad política, cuya existencia es reconocida adentro y afuera de su territorio, ha sido de reino hasta $1821 \mathrm{y}$ luego como República como llega hasta nuestros días. Incluso haber sido considerado para ser la Monarquía que agrupara a todos los territorios que hoy ocupan los países sudamericanos que formaban parte de la Monarquía Española, con independencia de ella, como lo concebía el Conde de Aranda en su Dictamen reservado que el excelentísimo Señor Conde de Aranda dio al Rey Carlos III sobre la independencia de las colonias inglesas después de haber hecho el tratado de paz ajustado en París en el año 1783. 
El concepto actual de peruano hay que entenderlo de manera extensiva, jamás restrictiva. A estas tierras han llegado todos. Si algo marca al Perú es su enorme capacidad de soportar casi todas las inmigraciones posibles que la humanidad puede proveer, desde los que cruzaron el estrecho de Bering, lo que vinieron de la polinesia con los primeros maorí que Túpac Yupanqui trajo a nuestras tierras como lo menciona José Antonio del Busto, europeos de todos sus lugares, asiáticos, africanos, unos llegaron primeros que otros, pero sin que eso de derechos superiores, hoy vivimos en una república bajo el principio liberal de la igualdad que debe regirnos, sin negar la diversidad cultural que es una de nuestras grandes riqueza. Pero sí en el camino de ir concluyendo la construcción del hombre peruano. No olvidemos que respiramos el mismo aire y tomamos la misma agua, ambos de nuestra cordillera andina, que derrama sus aguas también en la Amazonía. Somos peruanos, pero también andinos.

\section{CONCLUSIONES}

Pasando los grandes hitos en la construcción del ámbito geográfico y temporal de la peruanidad que hemos mencionado, estamos logrando el nuevo imaginario basado en los conceptos de patria y nación, sin embargo, construir una nación que identifique a todos quienes pueblan un territorio, es un proceso largo en el cual nos encontramos, pero felizmente avanzando y no retrocediendo, pero sin terminar la obra nueva, y voy a explicar esto.

Evidentemente no podemos afirmar que se ha terminado el diseño final de la peruanidad y menos de la andinidad. Ni tampoco del concepto Perú, que como todos no es pétreo sino dinámico. Reconocemos, como lo señala Heraclio Bonilla que: "La historia de los Andes es un proceso de yuxtaposición de parcelas de realidad cuya racionalidad remite a temporalidades distintas, sin que la matriz histórica que las alberga haya logrado resolver esa heterogeneidad otorgándole un tiempo y una unidad uniforme". (Bonilla, 2005, p. 30). Pero en esa ruta andamos.

El Perú, si bien nace como unidad política, definida en el tiempo y en el espacio, con la creación del Virreinato, en el imaginario es continuador histórico del pasado andino, y en igual forma, la República del Perú es la continuadora, no sólo jurídica, sino social y cultural del Virreinato. El proceso de colonización de su espacio no nació con la llegada del hombre europeo, este encontró colonizado, dominado el suelo, las aguas, la flora y la fauna de su cordillera, así como estructuras políticas, sociales, económicas, culturales y religiosas. No hay solución de continuidad en la historia peruana. 


\section{REFERENCIAS BIBLIOGRÁFICAS}

ALTUVE-FEBRES, Fernán

1996 Los Reinos del Perú. Apuntes sobre la monarquía peruana. Lima: Ed. Altuve y Dupuy.

ALVARADO DODERO, Fausto

2013 Virreinato o Colonia. Historia conceptual. España-Perú. Siglos XVI, XVII y XVIII. Lima: Fondo Editorial del Congreso del Perú.

BONILLA, Heraclio

2005 El futuro del pasado. Lima: Editorial del Pedagógico San Marcos.

CARRILLO, Francisco

1989 Cronistas de las Guerras Civiles. Así como del levantamiento de Manco Inca y el de don Lope de Aguirre llamado "la Ira de Dios". Lima: Editorial Horizonte.

DOMÍNGUEZ ORTIZ, Antonio

2010 América y la monarquía española. Granada: Comares.

FERNÁNDEZ, Javier

2004-2005 ¿Qué es un diccionario histórico de conceptos políticos?”. Internet Dialnet. Anales ISSN 1101-4148, Nos. 7-8, 2004-2005 pp. 223-240. Disponible: http://foroiberoideas.cervantesvirtual.com/ news/data/30.pdf,

KOSELLECK, Reinhart

1972 Introducción al diccionario histórico de conceptos político-sociales básicos en lengua alemana. Traducción y notas de Luis Fernández T. España: Revista Anthropos No. 223 pp. 92-1051999

LAVALLÉ, Bernard

2005 Francisco Pizarro. Biografia de una conquista. Lima: Instituto Francés de Estudios Andinos.

LEVENE, Ricardo

1973 Los Incas no eran colonias. Madrid: Colección Austral. Espasa Calpe. 
PEASE G.Y., Franklin

2007 Los Incas. Lima: Pontificia Universidad Católica del Perú, Fondo Editorial.

PÉREZ, Joseph

2012 La leyenda negra. Madrid: Gadir Editorial, S.L.

PORRAS BARRENECHEA, Raúl

2011 Historia de los límites del Perú. Perú: Fundación Manuel J. Bustamante de la Fuente.

RAMOS PÉREZ, Demetrio

2008 La Conquista. En Historia de Iberoamérica. II. Historia Moderna. Capítulo II Numeral 4. El Dominio del Mundo Andino, pp. 109-200.

REAL ACADEMIA ESPAÑOLA

2001 Diccionario de la Lengua Española (DRAE). 20ª ed. Madrid.

REGALADO, Liliana

2010 Historiografia Ocidental. Un tránsito por los predios de Clío. Lima: Pontificia Universidad Católica del Perú, Fondo Editorial.

1996 Sucesión Incaica. Lima: Pontificia Universidad Católica del Perú, Fondo Editorial.

RIVERO, Manuel

2011 La edad de oro de los virreyes. El virreinato en la Monarquía

Hispánica durante los siglos XVI y XVII. Madrid: Akal, 2011

ROSAS LAURO, Claudia

2006 Del trono a la guillotina. El impacto de la Revolución Francesa en el Perú (1789-1808). Lima: Pontificia Universidad Católica del Perú, Fondo Editorial-Instituto Francés de Estudios Andinos-Embajada de Francia.

SALVAT

1985 Diccionario enciclopédico. Barcelona: Salvat Editores

SOMEDA, Hidefuji

2005 El Imperio de los Incas. Imagen del Tahuantinsuyo creada por los cronistas. Lima: Lima: Pontificia Universidad Católica del Perú, Fondo Editorial. 
TANTALEÁN, Javier

2011 El virrey Francisco de Toledo y su tiempo. Proyecto de gobernabilidad, el imperio hispano, la plata peruana en la economía-mundo y mercado colonial. Vol. I. Lima: Universidad de San Martín de Porres, Fondo Editorial.

TENENTI, Alberti

2011 La Edad Moderna. XVI-XVIII. Barcelona: Crítica. Libros e Historia

THURNER, Mark

2012 En nombre del Abismo. Meditaciones sobre la historia de la historia. Lima: Instituto de Estudios Peruanos. 